\title{
Comparative characterization study of diatomites from different Brazilian locations and their application in dye adsorption
}

\author{
Severino H. da Silva Filho ${ }^{1}$. Paloma Vinaches ${ }^{1,3}$ (D) Habinadabe L. G. Silva ${ }^{1}$. Jhonny Villarroel-Rocha ${ }^{2}$. \\ Karim Sapag ${ }^{2}$ · Sibele B. C. Pergher ${ }^{1}$
}

Received: 16 August 2019 / Accepted: 18 October 2019 / Published online: 24 October 2019

(c) Springer Nature Switzerland AG 2019

\begin{abstract}
Diatomites are natural materials that are easily found around the world and require further study to achieve a systematic application in industry. In this study, we compared three Brazilian diatomites from different locations and found some similarities in their intrinsic characteristics that may be useful for removing contaminants, such as rhodamine $B$ and methylene blue. The samples were analyzed by X-ray diffraction, $X$-ray fluorescence, microscopy, thermogravimetry and mercury intrusion-extrusion porosimetry. Our findings on their porous structures were very interesting and explain their different behavior when adsorbing different dyes, thus, establishing a direct relationship between diatomite structure and application.
\end{abstract}

Graphic abstract

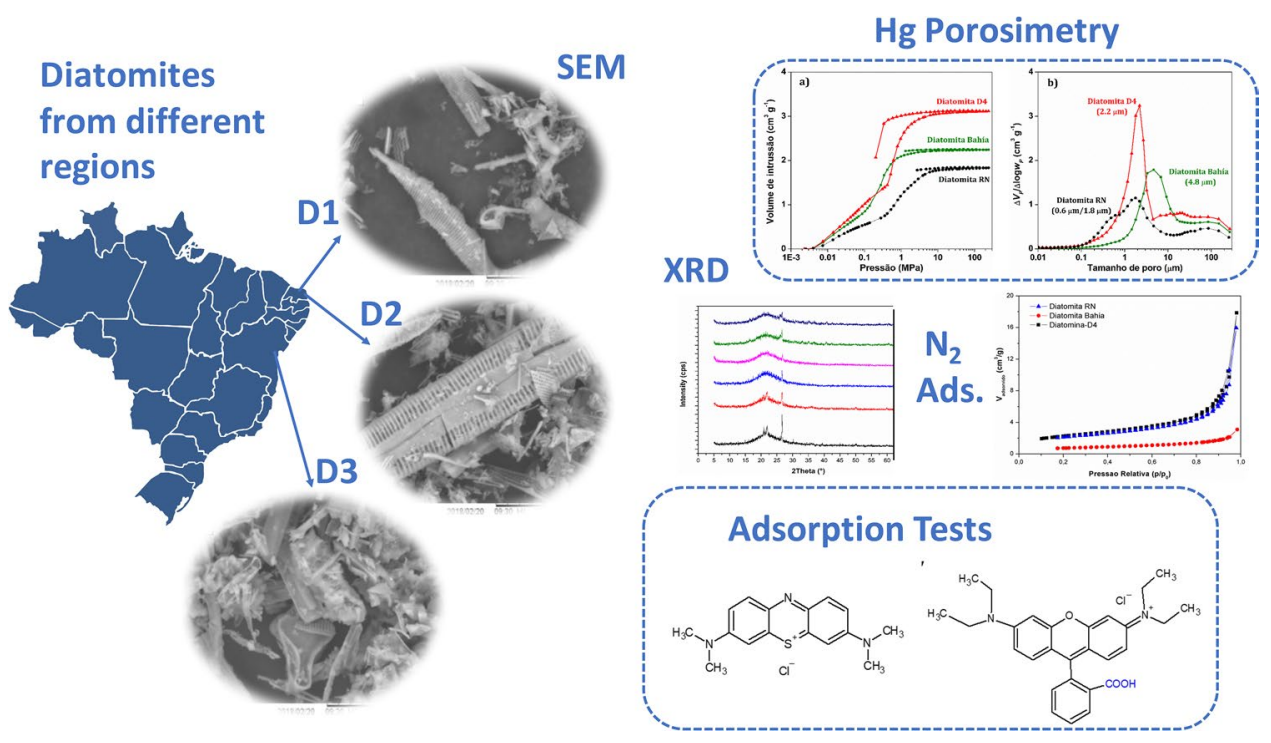

Keywords Diatomite $\cdot$ Characterization $\cdot$ Mercury intrusion-extrusion porosimetry $\cdot$ Rhodamine B $\cdot$ Methylene blue

$\triangle$ Paloma Vinaches, paloma.vinaches@Inls.br | ${ }^{1}$ Laboratório de Peneiras Moleculares, Universidade Federal do Rio Grande do Norte, Natal 59078-970, Brazil. ${ }^{2}$ Laboratorio de Sólidos Porosos, Instituto de Física Aplicada, CONICET-Universidad Nacional de San Luis, 5700 San Luis, Argentina. ${ }^{3}$ Present Address: Brazilian Synchrotron Light Laboratory (LNLS), Brazilian Center for Research in Energy and Materials (CNPEM), Campinas, São Paulo 13083-970, Brazil. 


\section{Introduction}

Diatomites are inorganic materials originating from rock sedimentation and formed by an accumulation of seaweed skeletons [1, 2]. These materials contain a large amount of silicon and some aluminum. They are usually applied as adsorbents and catalysts, for example, in the removal of $\mathrm{Zn}$ (II) from aqueous solutions [3] or as supports in the dry reforming of methane [4]. Another possible application is their use as alternative raw materials for green synthesis [5], in the same way that kaolin is used for zeolite synthesis [6]. Diatomites are inexpensive and available natural materials, but as their origins are diverse, it is interesting to perform a complete characterization and comparison for possible applications.

Removal of dyes from effluents is extremely important as they are toxic compounds, particularly under prolonged exposure and can cause various symptoms such as vomiting, diarrhea, increased heart rate and even necrosis of human tissues [7]. Examples of dyes are methylene blue, $\mathrm{C}_{13} \mathrm{H}_{18} \mathrm{~N}_{3} \mathrm{ClS}$, and rhodamine $\mathrm{B}, \mathrm{C}_{28} \mathrm{H}_{13} \mathrm{~N}_{2} \mathrm{O}_{3} \mathrm{Cl}$, which are both used in industry. Their chemical structures are shown in Fig. 1, and their difference in size is demonstrated. Several studies have proposed natural materials for adsorption [8-11]. However, due to the characteristics of natural products varying from one origin to another, the elimination of dyes from residual water is still a problem to solve. Some dye adsorption studies with diatomites have already been reported $[12,13]$, which shows the importance of continued testing to normalize their application with the origin of the natural material.

Due to the reported ability of diatomites as adsorbents in the literature, the aim of this work is to fully characterize and compare diatomites from different Brazilian locations and to study their application in the adsorption of methylene blue and rhodamine $B$.

\section{Materials and methods}

The diatomites studied in this article are from two Brazilian states: Rio Grande do Norte (denoted as D1 and D2, depending on the deposit in which they were obtained) and Bahia (denoted as D3).

These materials were characterized by X-ray fluorescence (XRF) on a Bruker S2 Ranger (Billerica, MA, USA) with $\mathrm{Pd}$ radiation, $\mathrm{a} \mathrm{Ag}$ anode and an XFlash ${ }^{\bullet}$ SiliconDrift detector. X-ray diffraction (XRD) measurements were obtained on a Bruker D2 Phaser (Billerica, MA, USA) with a LynxEye detector and $C u$ radiation. The samples were also studied by scanning electron microscopy (SEM) on a Hitachi TM3000 (Chiyoda, Tokyo, Japan). Thermogravimetric (TG/DTG) analysis was performed on a TA Instruments SDTQ600 equipment (New Castle, Delaware, USA) by weighing $10 \mathrm{mg}$ in a platinum crucible and using a $\mathrm{N}_{2}$ purge gas at $50 \mathrm{~mL} / \mathrm{min}$ with a heating rate of $10^{\circ} \mathrm{C} / \mathrm{min}$. Measurements of mercury intrusion-extrusion porosimetry for the materials under study were carried out using a porosimeter Autopore III 9410 (Micromeritics, Norcross, GA, USA) from 0.002 up to $240 \mathrm{MPa}$.

The experiments adsorbing the dyes rhodamine $B$ (Sigma-Aldrich, $\geq 95 \%$ ) or methylene blue (Sigma-Aldrich, $\geq 95 \%$ ) were performed in triplicate. The three diatomites were separately used as adsorbents (one diatomite per adsorption experiment). First, a 7 ppm solution of a chosen dye was prepared in deionized water. Second, 50-mL aliquots of the previous solution were transferred to several Erlenmeyer flasks containing $100 \mathrm{mg}$ of the chosen diatomite. The suspensions were stirred for different times (2, 5, 10 and $20 \mathrm{~min})$. Subsequently, $4 \mathrm{~mL}$ of the resulting solution was filtered through $0.2-\mu \mathrm{m}$ nylon filters, and the solution was read in a spectrophotometer (HachDR500), recording the absorbances at a $553 \mathrm{~nm}$ wavelength for rhodamine $B$ or at a $665 \mathrm{~nm}$ wavelength for methylene blue. The concentration of the measured solutions was obtained after applying the Lambert-Beer equation [15]: Abs $=a \cdot b \cdot c$, where Abs is the absorbance, $c$ is the concentration in ppm, $b$ is the optical path $(1 \mathrm{~cm})$,

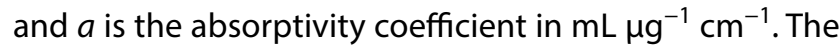
efficiency was calculated by having previously measured
Fig. 1 Representation of rhodamine $B(\mathbf{a})$ and methylene blue (b) using a free version of ChemSketch [14]<smiles>CCN(CC)c1ccc2c(-c3ccccc3C(=O)O)c3ccc(=[N+](CC)CC)cc-3oc2c1</smiles>

B<smiles>CN(C)c1ccc2nc3ccc(N(C)C)cc3[s+]c2c1</smiles> 
Table 1 Composition of diatomites

\begin{tabular}{lccc}
\hline $\begin{array}{l}\text { Composition in oxide } \\
\text { form }\end{array}$ & D1 (\%) & D2 (\%) & D3 (\%) \\
\hline $\mathrm{SiO}_{2}$ & 94.4 & 90.0 & 81.0 \\
$\mathrm{Al}_{2} \mathrm{O}_{3}$ & 3.4 & 6.4 & 11.5 \\
$\mathrm{MgO}$ & 1.2 & 1.3 & 1.7 \\
$\mathrm{TiO}_{2}$ & 0.2 & 0.2 & 2.0 \\
$\mathrm{Fe}_{2} \mathrm{O}_{3}$ & 0.3 & 0.6 & 1.5 \\
$\mathrm{Na}_{2} \mathrm{O}$ & 0.3 & 0.4 & 1.5 \\
Others & 0.2 & 1.1 & 0.8 \\
\hline
\end{tabular}

the exact concentration of the starting solution in the spectrophotometer. The formula used was [16]: efficiency $(\%)=100 \cdot\left(c_{0}-c\right) / c_{0}$, where $c_{0}$ is the initial concentration and $c$ is the concentration measured at the time of adsorption.

\section{Results and discussion}

The three diatomite samples, D1, D2 and D3, were analyzed by X-ray fluorescence (XRF). Table 1 collects the results, showing that their composition was essentially $\mathrm{Si}$ and $\mathrm{Al}$, with $\mathrm{D} 3$ having a higher aluminum content than $\mathrm{D} 1$ and $\mathrm{D} 2$. The $\mathrm{Si} / \mathrm{Al}$ ratios of the diatomites resulted in 23.6, 11.9 and 6.0 for D1, D2 and D3, respectively. Comparing our $\mathrm{Si} / \mathrm{Al}$ results to those obtained by Yuan et al. [17] on the chemical composition of diatomites from China ( $\mathrm{Si} / \mathrm{Al}=8.4)$, Australia ( $\mathrm{Si} / \mathrm{Al}=20.6)$ and the USA (Si/ $\mathrm{Al}=12.6)$, we found a wider Si/Al range in just one country, so it is necessary to choose the diatomite with the needed composition.

X-ray diffraction (XRD) results of the diatomite samples are shown in Fig. 2. All the diffractograms were characteristic of amorphous materials, which is the representative phase of diatomites accompanied by a quartz impurity $\left(2 \theta=21^{\circ}\right.$ and $\left.27^{\circ}\right)$. Sample D2 contained the highest quartz content, as the intensity of the Bragg reflection corresponding to quartz was the highest among all the samples.

The micrographs from scanning electron microscopy (SEM) (Fig. 3) presented the samples as inhomogeneous objects with different particle sizes and shapes, such as navicular morphology or fishbones. Some of these structures were also coincident with those reported by Liu et al. [18] for Chinese diatomites.

The thermogravimetric analyses of the three diatomites (Fig. 4) presented a single event: a mass loss of $1-2 \%$ until approximately $250{ }^{\circ} \mathrm{C}$, which is related to the adsorbed water and unidentified small organic molecules possibly adsorbed on the surface or inside

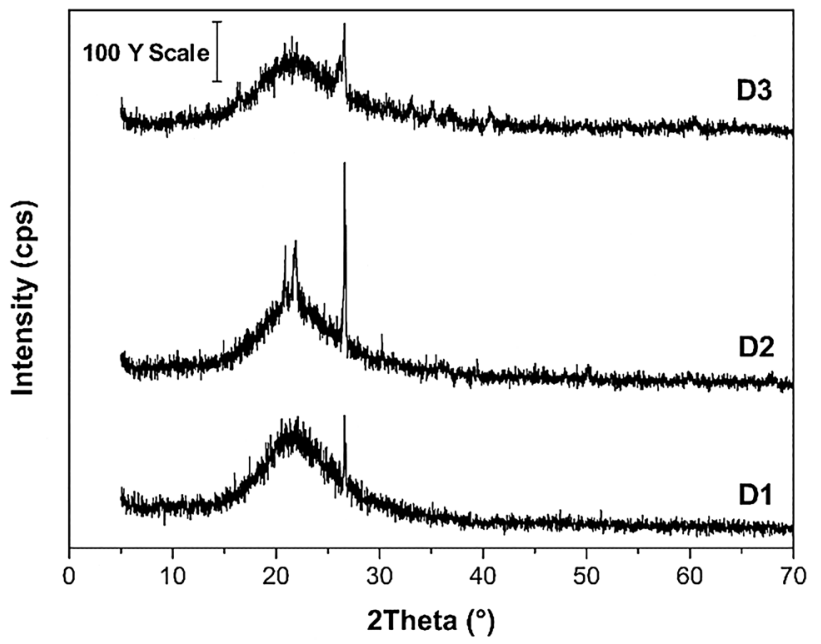

Fig. 2 X-ray diffractograms of the diatomite samples

the pores. Different porosity probably caused the small variations observed between the diatomites, as we will explain later.

The three diatomites were studied by mercury intrusion-extrusion porosimetry because macropores appeared in the SEM micrographs. The resulting curves are shown in Fig. 5. The results presented an abrupt mercury intrusion (in the pressure range of $0.01-10 \mathrm{MPa}$ ), indicating that the samples presented a well-defined porosity in the macropore range, as shown in a pore size distribution (PSD). The PSD profile of the samples has a unimodal distribution with modal pore sizes of $1.8 \mu \mathrm{m}, 2.2 \mu \mathrm{m}$ and $4.8 \mu \mathrm{m}$ for D1, D2 and D3, respectively. The macropore sizes of these Brazilian diatomites were larger than those reported by Liu et al. [18] describing a modal macropore size of $0.7 \mu \mathrm{m}$.

The textural properties of the samples are shown in Table 2. Sample D1 had the highest density (bulk and skeletal) and consequently the lowest total pore volume. Sample D3 presented the lowest specific surface area, porosity and skeletal density. These differences between the samples seemed to be the cause of the different losses found in the thermogravimetric analysis, as different quantities of small molecules could be adsorbed on the pores or the surface depending on how porous a material is. This fact justified our interest in testing dye adsorption as a less expensive and natural alternative for decontamination.

The dye adsorption experiments were started by obtaining two calibration curves, one per dye that allowed us to experimentally calculate the absorptivity coefficients according to the Lambert-Beer law by linear adjustment. The values of these coefficients were $0.12 \mathrm{~mL} \mathrm{\mu g}^{-1} \mathrm{~cm}^{-1}$ for methylene blue $\left(R^{2}=0.9995\right)$ and $0.20 \mathrm{~mL} \mathrm{\mu g}^{-1} \mathrm{~cm}^{-1}$ for rhodamine $B\left(R^{2}=0.9999\right)$. 
Fig. 3 Micrographs of the D1 (a), D2 (b) and D3 (c) diatomites

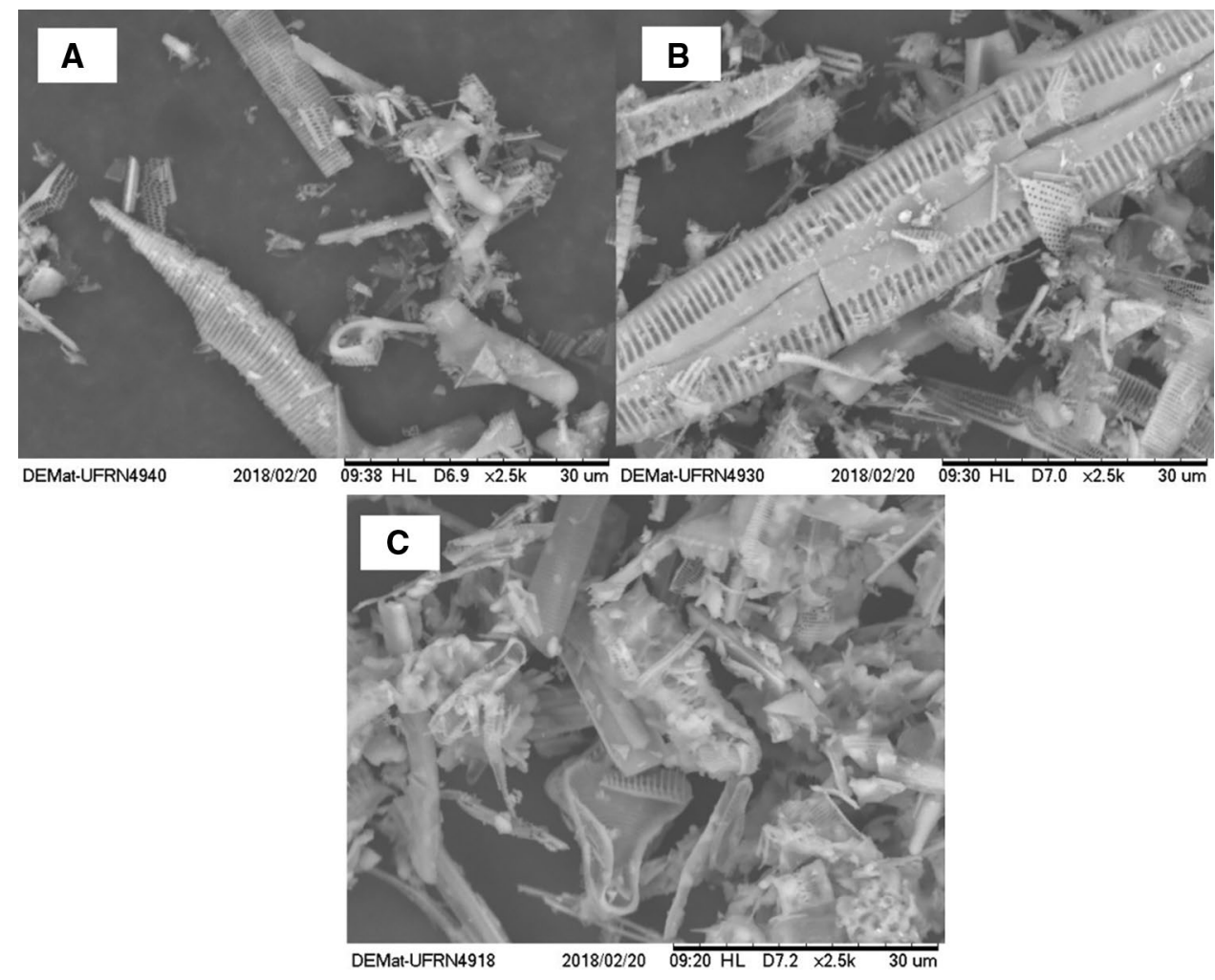

Fig. 4 Thermogravimetric curves of the diatomites (TG/ DTG)

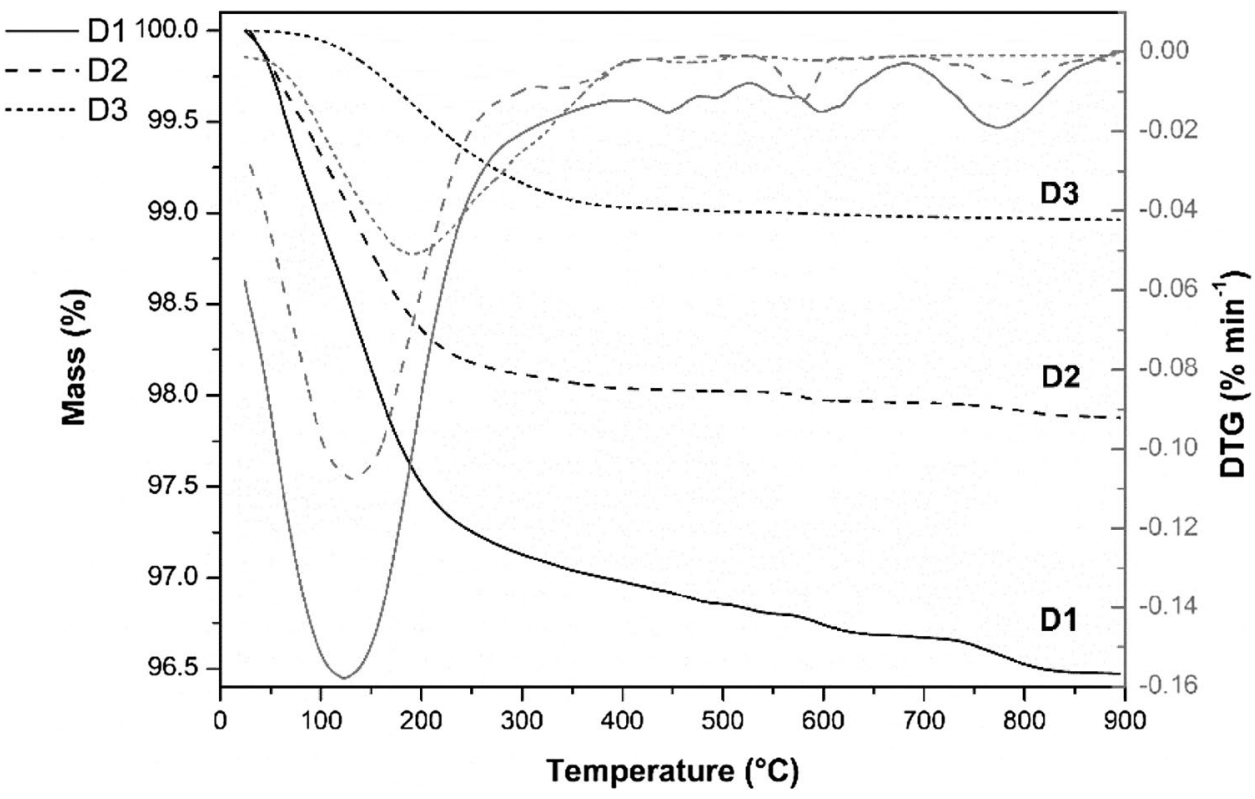

Then, the adsorption experiments were continued by testing rhodamine $B$ as a contaminant. The results are shown in Fig. 6a. The three diatomites reached equilibrium after $10 \mathrm{~min}$, with an adsorption efficiency of approximately $65 \%$ for all the materials. This maximum value is due to the larger size of the rhodamine B molecule, which probably did not differentiate between the pores and the external surface as adsorption sites.
Methylene blue adsorption results (Fig. 6b) were more interesting for these materials. The maximum adsorption (96\%) and equilibrium was rapidly reached after 2 min of adsorption when testing the $\mathrm{D} 2$ diatomite. This result was directly related to $D 2$ having the highest porosity and pore volume. The other two diatomites achieved their maximum adsorptions and equilibrium after $5 \mathrm{~min}$, adsorbing $90 \%$ and $77 \%$ in D3 and D1, respectively. Again, these 

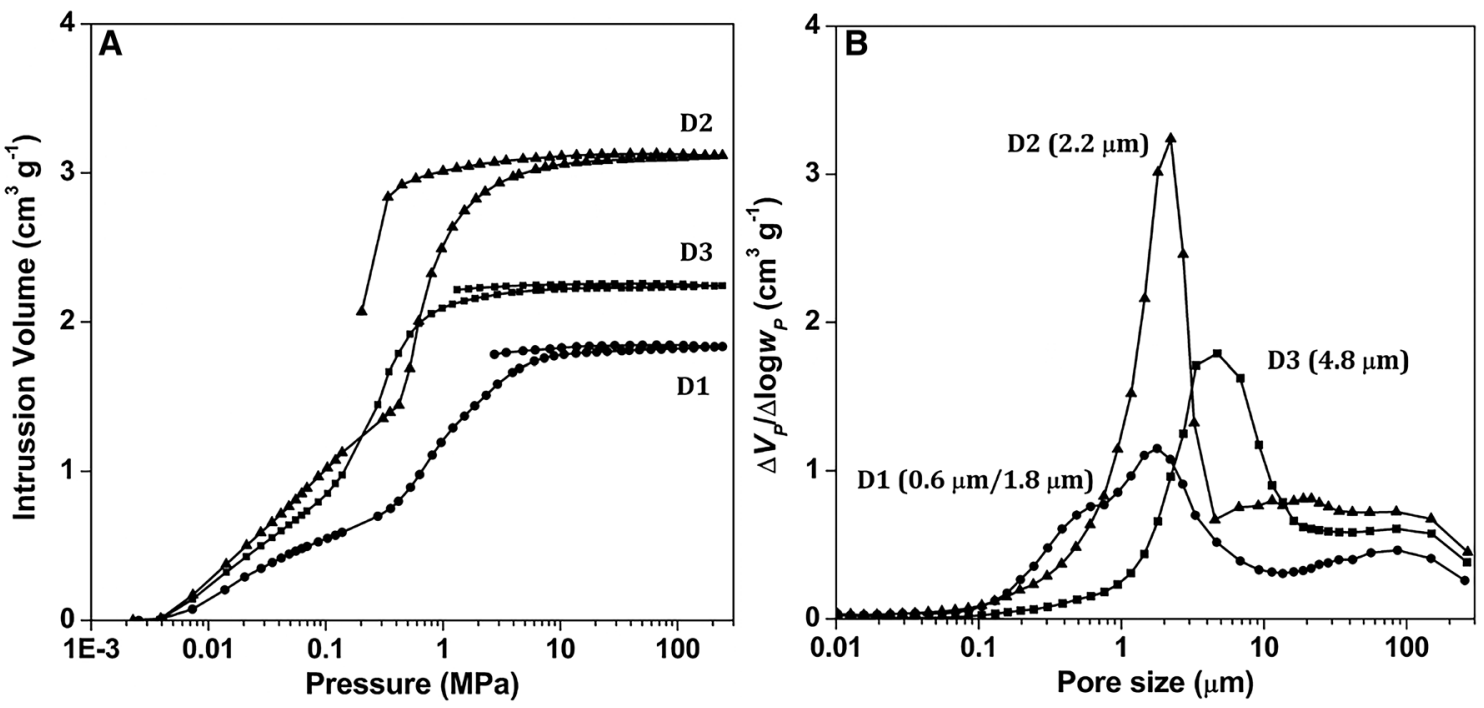

Fig. 5 Mercury intrusion-extrusion curves (a) and pore size distribution of the diatomite samples (b). Three different symbols show the different data for the D1 (spheres), D2 (triangles) and D3 (squares) diatomites

Table 2 Textural properties of the diatomite samples

\begin{tabular}{llllll}
\hline Materials & $\begin{array}{l}\mathrm{S}_{\mathrm{Hq}}\left(\mathrm{m}^{2}\right. \\
\left.\mathrm{g}^{-1}\right)\end{array}$ & $\begin{array}{l}V_{\mathrm{p}}\left(\mathrm{cm}^{3}\right. \\
\left.\mathrm{g}^{-1}\right)\end{array}$ & $\begin{array}{l}\text { Porosity } \\
(\%)\end{array}$ & $\begin{array}{l}\rho_{\mathrm{A}} \\
\left(\mathrm{g} \mathrm{cm}^{-3}\right)\end{array}$ & $\rho_{B}\left(\mathrm{~g} \mathrm{~cm}^{-3}\right)$ \\
\hline D1 & 17 & 1.83 & 78 & 0.42 & 1.91 \\
D2 & 18 & 3.12 & 84 & 0.27 & 1.62 \\
D3 & 9 & 2.24 & 60 & 0.27 & 0.67 \\
\hline
\end{tabular}

Specific surface area $\left(S_{\mathrm{Hg}}\right)$, total pore volume $\left(V_{\mathrm{p}}\right)$, bulk density $\left(\rho_{A}\right.$ density of the material that constitute the particle, with porosity), skeletal density $\left(\rho_{B}\right.$ density of the material that constitute the particle, without porosity) results were in accordance with the order of pore volume observed with the mercury intrusion-extrusion porosimetry analysis.

In agreement with the results from both dye adsorption experiments, the porous structure of the diatomites proved to be an important characteristic directly related to the efficiency of the application. Another characteristic important for the dye-diatomite interaction is the hydroxyl species and acid sites present on the diatomite surface. This type of research was already performed by
Fig. 6 Experimental data from the adsorption experiments: rhodamine B (a) and methylene blue (b). The efficiency was calculated from the measurements performed after 2, 510 and $20 \mathrm{~min}$ of adsorption. Each diatomite is represented by a color and a pattern (D1: light gray—forward slash; D2: dark gray—backslash; D3: whitezigzag)

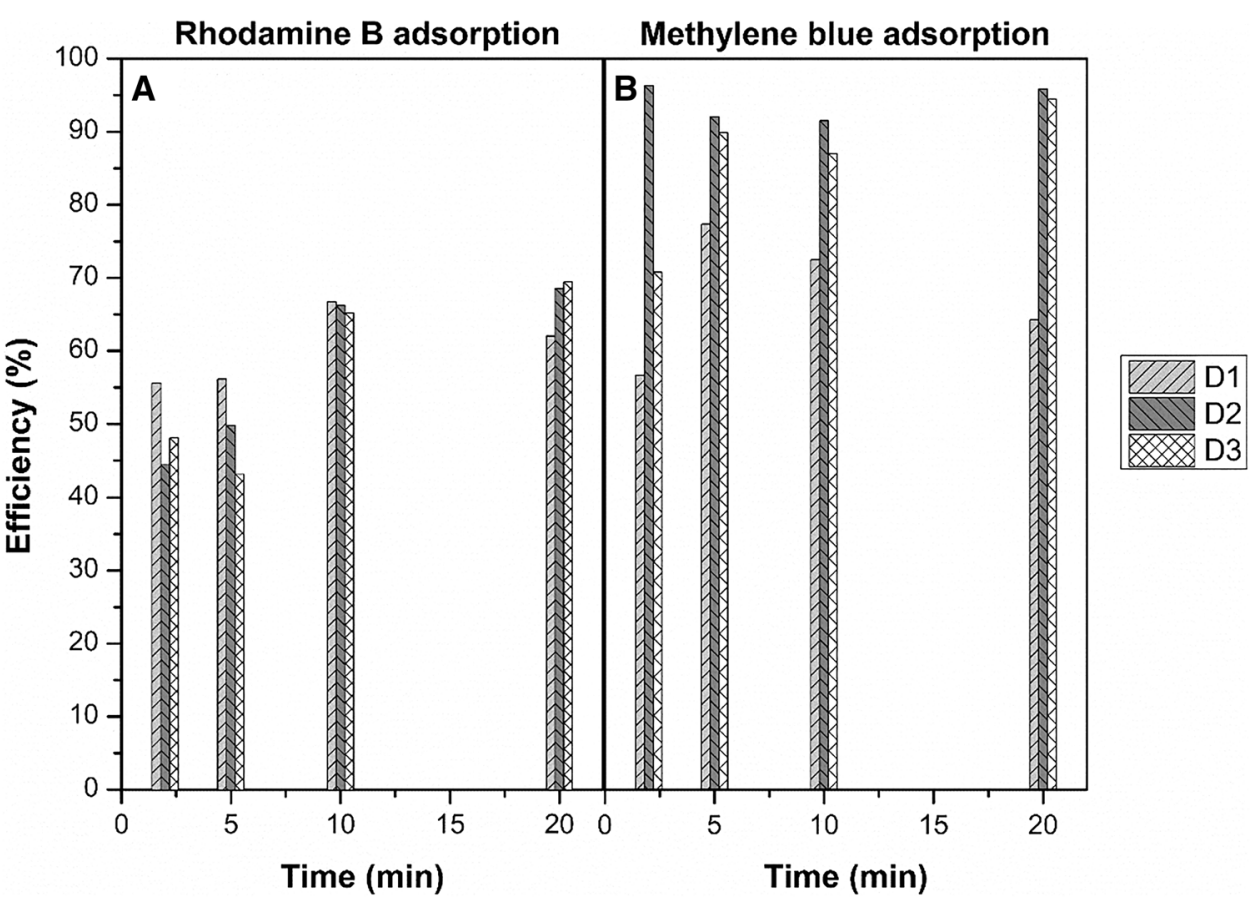

SN Applied Sciences 
Yuan et al. [19] studying several Chinese diatomites. As a proposal for further study, it will be interesting to continue with a comparative study between Brazilian and Chinese diatomites.

\section{Conclusions}

The complete characterization of the diatomite samples shows that they are amorphous heterogeneous materials, and their differences in composition and porosity are the main interests for possible applications. In this article, we tested two different contaminant dyes for adsorption in Brazilian diatomites. Our results showed a direct relationship between the adsorption efficiency and the pore structure and volume. For instance, our analysis of the mercury porosimetry data presented the D3 diatomite as the material with the smallest specific area, porosity and apparent density. Moreover, the D1 diatomite had the highest bulk and apparent densities but the lowest total pore volume. When these materials were tested in adsorption, the D2 diatomite showed a better removal efficiency of methylene blue; the dye removal efficiency of the other diatomites followed the same order as their pore volume. However, testing rhodamine $B$ resulted in equal efficiencies for all the samples due to the larger size of the dye molecule.

In conclusion, even though the different intrinsic characteristics of the diatomites proved to influence their performance under a certain application, these materials were good dye adsorbents. Thus, better knowledge of the diatomite structures from different origins will help tailor their use for more efficient results. This research work focused on Brazilian diatomites to be able to transfer the knowledge to industry in a way that it would be possible to apply them directly. The application chosen was directly related to one of the most concerning problems, which is existing contamination, and the characterization results indicated which of the diatomite sources would be best for particular cases. Other contaminants may be chosen for future work and tested following the description presented in this article.

Acknowledgements The authors acknowledge LABPEMOL, PPGQ, UFRN and UNSL for characterization and adsorption experiments at their facilities.

Authors' contribution Conceptualization and Methodologies: SHSF, PV and SBCP; Characterization: SHSF, PV, JVR and KS; Dye adsorption: SHSF, PV and HLGS; Writing: SHSF, PV; HLGS; JVR, KS and SBCP.

Funding This study was partially funded by CNPQ (doctoral scholarship for Severino H. da Silva Filho).

\section{Compliance with ethical standards}

Conflict of interest The authors declare that they have no conflict of interest.

\section{References}

1. Fragoulis D, Stamatakis MG, Chaniotakis E, Columbus G (2004) Characterization of lightweight aggregates produced with clayey diatomite rocks originating from Greece. Mater Charact 53:307-316. https://doi.org/10.1016/j.matchar.2004.05.004

2. Ivanov SÉ, Belyakov AV (2008) Diatomite and its applications. Glass Ceram 65:48-51. https://doi.org/10.1007/s1071 7-008-9005-6

3. Caliskan N, Kul AR, Alkan S et al (2011) Adsorption of Zinc(II) on diatomite and manganese-oxide-modified diatomite: a kinetic and equilibrium study. J Hazard Mater 193:27-36. https://doi. org/10.1016/j.jhazmat.2011.06.058

4. Jabbour K, El Hassan N, Davidson A et al (2015) Characterizations and performances of $\mathrm{Ni} /$ diatomite catalysts for dry reforming of methane. Chem Eng J 264:351-358. https://doi.org/10.1016/j. cej.2014.11.109

5. Chaisena A, Rangsriwatananon K (2005) Synthesis of sodium zeolites from natural and modified diatomite. Mater Lett 59:1474-1479. https://doi.org/10.1016/j.matlet.2004.10.073

6. EL-Mekkawi DM, Selim MM (2012) Effect of metal loading processes on the stability and thermal transformation of $\mathrm{Co}^{2+}$ - and $\mathrm{Cu}^{2+}$-zeolite $\mathrm{Y}$ prepared from Egyptian kaolin. Mater Charact 69:37-44. https://doi.org/10.1016/j.matchar.2012.04.001

7. Ghosh D, Bhattacharyya KG (2002) Adsorption of methylene blue on kaolinite. Appl Clay Sci 20:295-300. https://doi. org/10.1016/S0169-1317(01)00081-3

8. Mohd Rafatullah, Sulaiman O, Hashim R, Ahmad A (2010) Adsorption of methylene blue on low-cost adsorbents: a review. J Hazard Mater 177:70-80. https://doi.org/10.1016/j.jhazm at.2009.12.047

9. Benhamouda K, Sehili T, Djebbar K (2016) Adsorption of rhodamine $B$ and methylene blue in solution using an Algerian iron oxide. Res J Pharm Biol Chem Sci 7:2486-2492

10. Damiyine B, Guenbour A, Boussen R (2017) Rhodamine B adsorption on natural and modified moroccan clay with cetyltrimethylammonium bromide: kinetics, equilibrium and thermodynamics. J Mater Environ Sci 8:860-871

11. Duarte Neto JF, Pereira IDS, Da Silva VC et al (2018) Study of equilibrium and kinetic adsorption of rhodamine $B$ onto purified bentonite clays. Ceramica 64:598-607. https://doi. org/10.1590/0366-69132018643722429

12. Erdem $E$, Çölgeçen $G$, Donat $R$ (2005) The removal of textile dyes by diatomite earth. J Colloid Interface Sci 282:314-319. https:// doi.org/10.1016/j.jcis.2004.08.166

13. Lin JX, Zhan SL, Fang MH, Qian XQ (2007) The adsorption of dyes from aqueous solution using diatomite. J Porous Mater 14:449-455. https://doi.org/10.1007/s10934-006-9039-5

14. ACD/ChemSketch (freeware) (2017) Advanced Chemistry Development, Inc., Toronto, ON, Canada

15. Skoog DA, West DM, Holler FJ, Stanley RC (2013) Fundamentals of analytical chemistry, 9th edn. Cengage Learning, Boston

16. Carvalho T, Fungaro D, Izidoro J (2010) Adsorção do corante reativo laranja 16 de soluções aquosas por zeólita sintética. Quim Nova 33:358-363

17. Yuan P, Liu D, Zhou J et al (2019) Identification of the occurrence of minor elements in the structure of diatomaceous opal 
using FIB and TEM-EDS. Am Miner 104:1323-1335. https://doi. org/10.2138/am-2019-6917

18. Liu D, Yuan P, Tan D et al (2012) Facile preparation of hierarchically porous carbon using diatomite as both template and catalyst and methylene blue adsorption of carbon products. J Colloid Interface Sci 388:176-184. https://doi.org/10.1016/j. jcis.2012.08.023

19. Yuan P, Wu DQ, He HP, Lin ZY (2004) The hydroxyl species and acid sites on diatomite surface: a combined IR and Raman study. Appl Surf Sci 227:30-39. https://doi.org/10.1016/j.apsus c.2003.10.031

Publisher's Note Springer Nature remains neutral with regard to jurisdictional claims in published maps and institutional affiliations. 